\title{
Significance of Right Bundle-branch Block Patterns During Pervenous Ventricular Pacing ${ }^{\star}$
}

\author{
S. SERGE BAROLD, ONKAR S. NARULA, ROGER P. JAVIER, JOSEPH W. LINHART \\ JOHN W. LISTER, AND PHILIP SAMET $\ddagger$ \\ From the Division of Cardiology, Department of Internal Medicine, Mount Sinai Hospital, Miami Beach,
and the University of Miami School of Medicine, Coral Gables, Florida, U.S.A.
}

Despite the widespread use of pervenous right ventricular pacing, there are relatively few reports concerning the occurrence of a right bundle-branch block pattern during apparent right ventricular pacing (Siddons and Sowton, 1967; Mower, Aranaga, and Tabatznik, 1967). This communication presents our observations of these patterns during pervenous ventricular pacing and analyses their clinical and electrophysiological implications.

\section{CASE Reports}

Case 1. A 78-year-old man was admitted with an acute inferior wall myocardial infarction and complete right bundle-branch block. A bipolar pacing catheter was passed at the bedside without fluoroscopy to what was thought to be the right atrium for recording atrial electrograms, to determine the mechanism of a supraventricular tachycardia which developed soon after admission. Ventricular tachycardia supervened during the procedure and cardioversion established sinus rhythm. The patient's clinical course was subsequently uneventful except for transient atrial flutter. Two days later ventricular pacing could be achieved only at a high threshold (22 $\mathrm{mA})$, and the electrocardiogram demonstrated a right bundle-branch block pattern in the praecordial leads during ventricular pacing (Fig. 1). Electrograms, recorded from the tip electrode (Gordon, 1965) before and during the withdrawal of the catheter, suggested that it had been located in the coronary sinus (Fig. 2).

Case 2. A 75-year-old man was admitted for the treatment of complete heart block and Adams-Stokes attacks. The electrocardiogram showed complete heart

Received August 12, 1968.

* Supported by United States Public Health Service Grant.

† Present address: Department of Physiology and Internal Medicine, University of Texas School of Medicine, San Antonio, Texas, U.S.A.

‡ Address for reprints: Dr. Philip Samet, Mount Sinai Hospital, 4300 Alton Road, Miami Beach, Florida, U.S.A. block with a $0.13 \mathrm{sec}$. QRS complex with a left bundlebranch block pattern. A temporary bipolar pacing catheter was inserted into what was considered to be the outflow tract of the right ventricle, and ventricular pacing was achieved at a threshold of about 4-5 $\mathrm{mA}$. Several days later when the threshold had risen to $22 \mathrm{~mA}$ and the chest $x$-ray suggested that the catheter was in the coronary sinus, the significance of the right bundlebranch block pattern recorded in the electrocardiogram (Fig. 3) became evident. The catheter was withdrawn and replaced by another which was positioned in the outflow tract of the right ventricle where a left bundlebranch block pattern was recorded during pacing (Fig. 3).

Case 3. Cardiac catheterization demonstrated no abnormality in a 16-year-old boy who had been referred for the investigation of a cardiac murmur and incomplete right bundle-branch block in the electrocardiogram. At the end of the study, a bipolar pacing catheter was manipulated, in turn, to the outflow tract, apex, and inflow tract of the right ventricle, and surface electrocardiograms were obtained during pacing at these sites (Fig. 4, 5, and 6). The pacing rate, which was faster than the control rate, and voltage used for pacing were identical for all the three sites. A right bundle-branch block pattern was recorded during pacing of the apex of the right ventricle and retrograde ventriculo-atrial conduction with reciprocal (echo) beating was also observed (Fig. 7). Electrograms before pacing at all the sites demonstrated intraventricular morphology, and the threshold for ventricular pacing was under $1.5 \mathrm{~mA}$ at all sites.

Case 4. An 86-year-old man was admitted with congestive heart failure and the electrocardiogram demonstrated atrial fibrillation and complete heart block with a 0.13 sec. QRS complex exhibiting a right bundlebranch block pattern. When he became compensated, a permanent pervenous pacemaker was implanted with the tip of the catheter wedged in the apex of the right ventricle where the threshold for pacing was $0.5 \mathrm{~mA}$, and the electrogram displayed an intraventricular QRS complex. After operation the electrocardiogram showed 


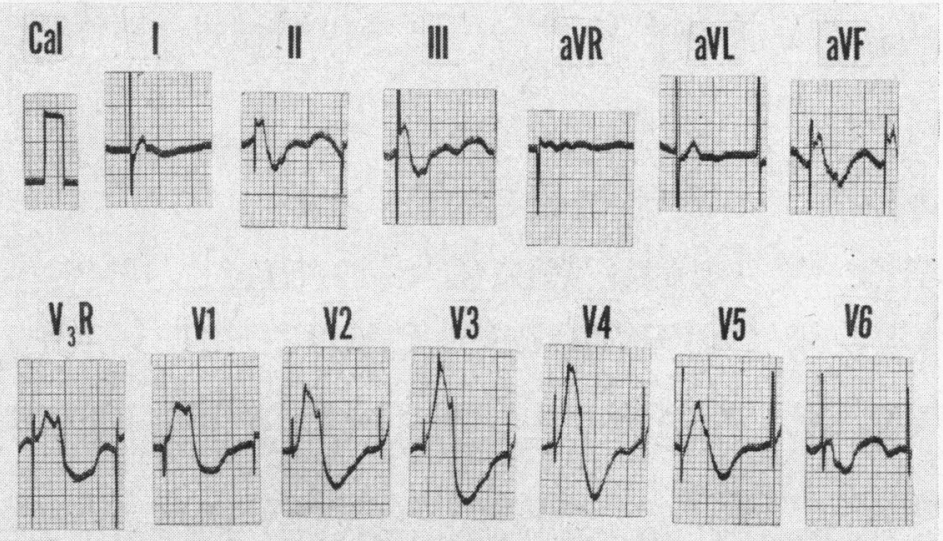

FIG. 1.-Case 1: electrocardiogram shows right bundle-branch block pattern when ventricular pacing has been achieved from the coronary sinus.

a right bundle-branch block pattern in the praecordial leads (Fig. 8). No clinical evidence of perforation was apparent and pacing has remained regular for several months.

\section{Discussion}

During ventricular pacing the configuration of the QRS complex depends upon the site of stimulation. Pacemaker wires attached to the left ventricle

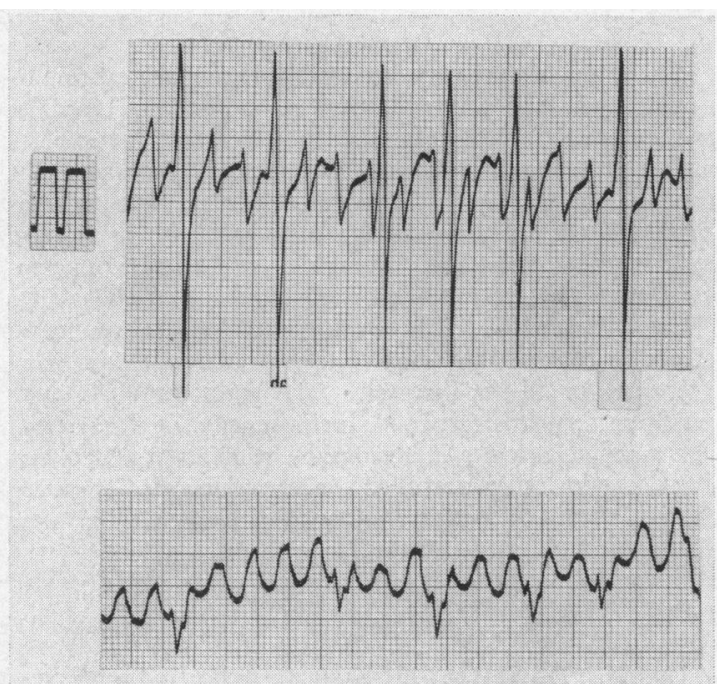

FIG. 2.-Upper strip. Electrogram from the tip electrode when the pacing catheter was in the coronary sinus. Note the prominent peaked atrial flutter waves and the high QRS complex voltage. Lower strip. Electrogram from the tip electrode after the catheter was withdrawn to the right atrium. Note the striking flutter waves which are now morphologically different, and the relatively low voltage QRS complex. During the withdrawal of the catheter from the coronary sinus to the right atrium, at no time did the striking atrial flutter waves disappear. are expected to produce delayed activation of the right ventricle and a right bundle-branch block pattern in the electrocardiogram. In contrast, pacing of the right ventricle by either the epicardial or endocardial approach almost invariably produces a left bundle-branch block pattern in the electrocardiogram.

A right bundle-branch block pattern may be registered during pervenous ventricular pacing when

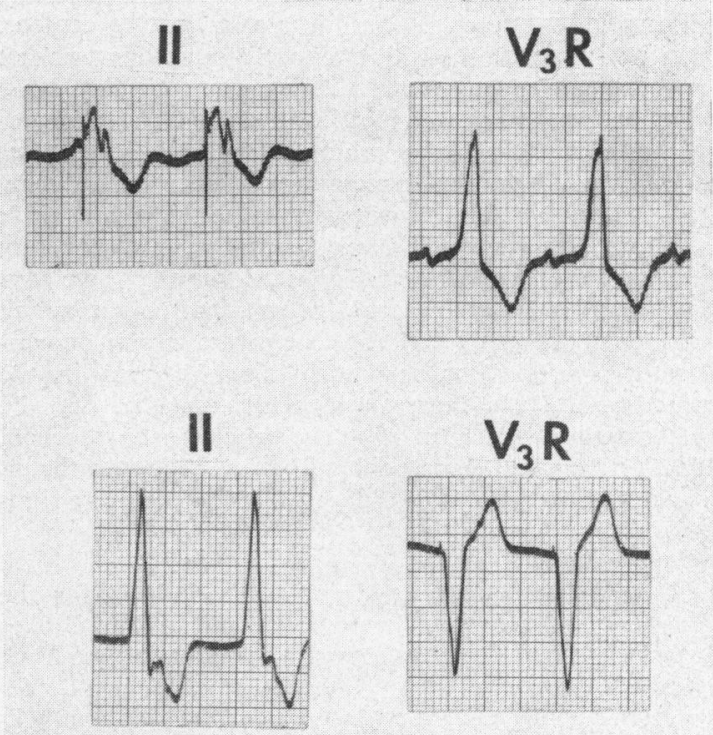

FIG. 3.-Case 2: upper portion shows leads II and V3R during coronary sinus pacing. Note the right bundle-branch block pattern in V3R. Lower portion shows leads II and V3R during right ventricular outflow tract pacing. Note the left bundlebranch block pattern in V3R. 


\section{OUTFLOW}

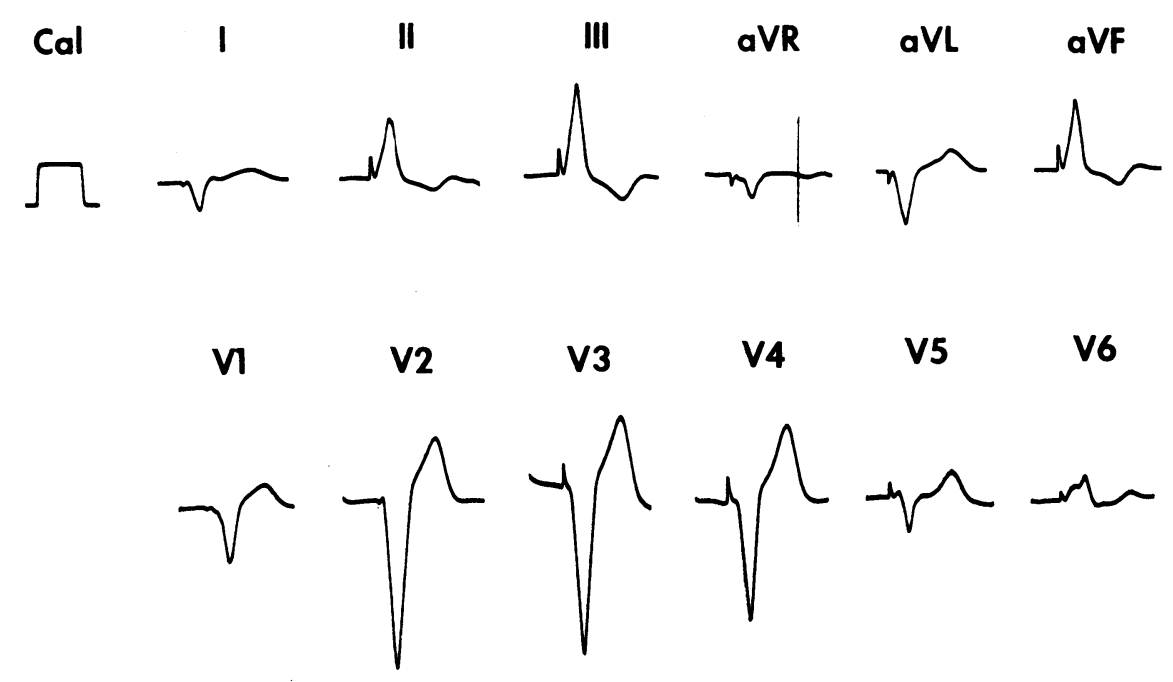

Fig. 4. - Case 3: electrocardiogram during pacing of the right ventricular outflow tract showing an rS pattern in leads I and aVL, and left bundle-branch block pattern in the praecordial leads.

the left ventricle becomes activated before the right ventricle. Left ventricular excitation may occur before right ventricular depolarization when electrical stimuli are actually delivered preferentially to the left ventricle because of malposition of a catheter either in the coronary sinus or consequent to a perforation through the right ventricular wall or the septum. Siddons and Sowton (1967) pointed out that a pacing catheter situated in the coronary sinus (and along a coronary vein) may stimulate the epicardial surface of the left ventricle yielding a right bundle-branch pattern. However, Mower et al.

\section{INFLOW}
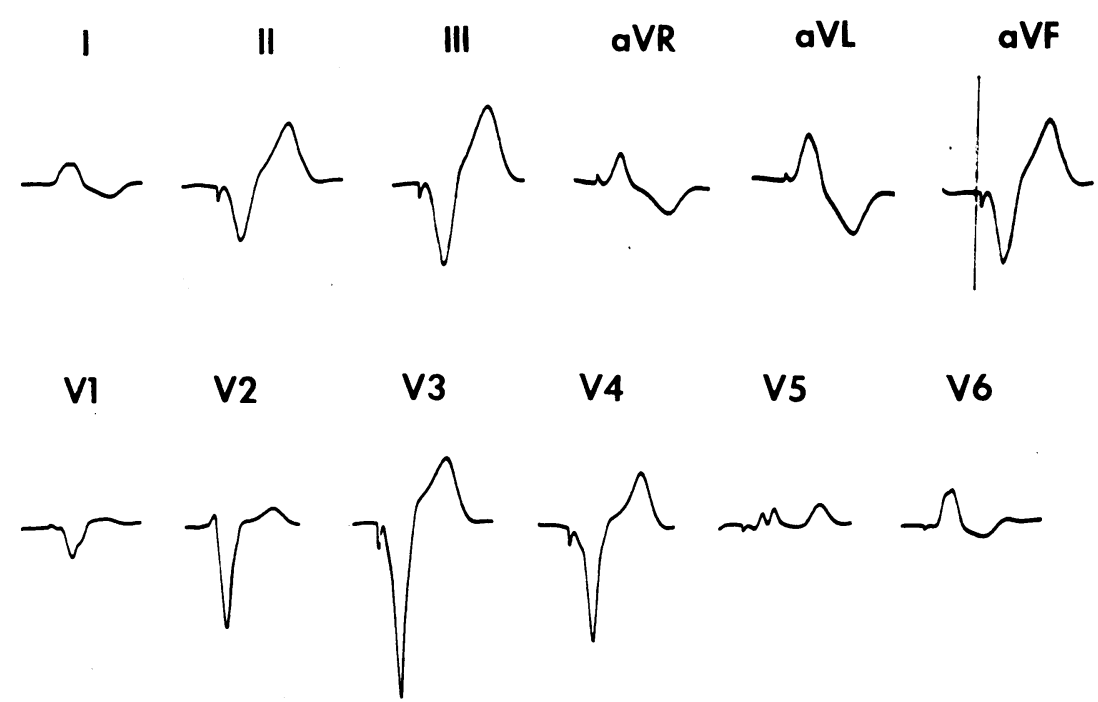

FIG. 5.-Case 3: electrocardiogram during pacing inflow tract of right ventricle, showing left bundle-branch block pattern. 


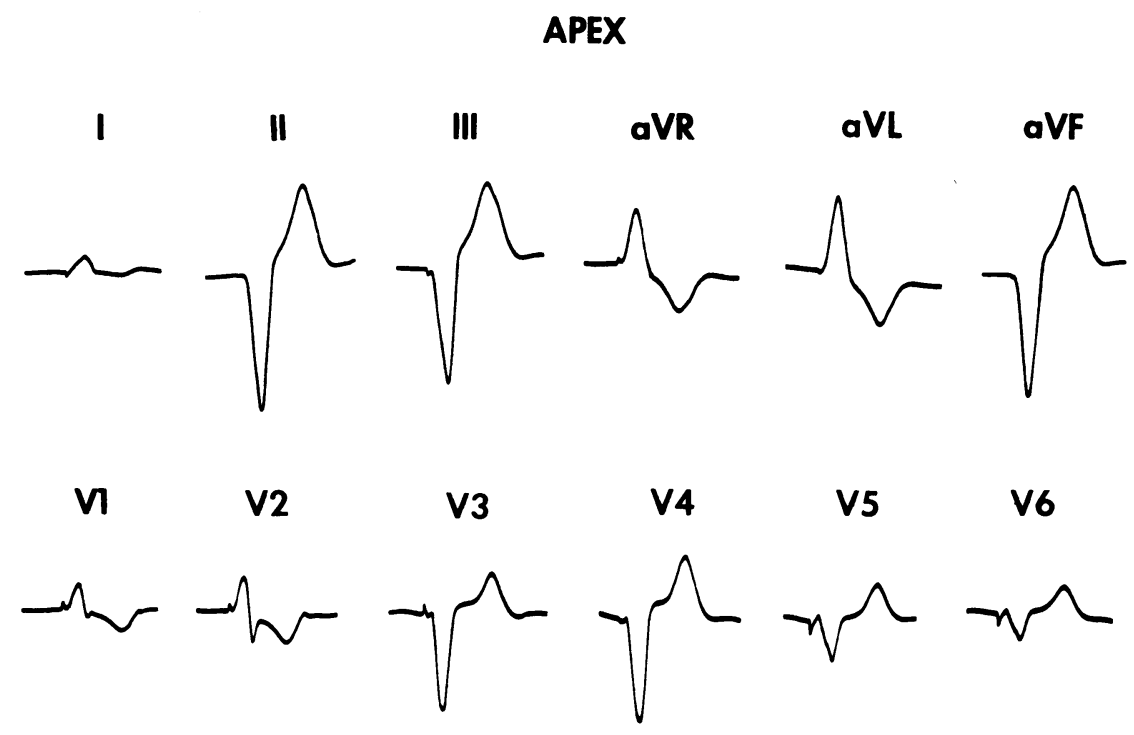

FrG. 6.-Case 3: electrocardiogram during pacing of the apical portion of the right ventricle. A right bundlebranch block pattern is evident in the praecordial leads, while leads I and aVL show a left bundle-branch block pattern.

(1967) who investigated the problem of right bundlebranch block conduction pattern during pervenous pacing were unable to obtain such a configuration during coronary sinus stimulation. Ventricular pacing from the coronary sinus, which represents a form of indirect stimulation akin to external pacing, is generally difficult to achieve because of the high initial threshold which tends to rise rapidly over the course of a few days (Gordon, 1965; Siddons and Sowton, 1967). Right bundle-branch block patterns were obtained in two patients whose catheters were considered to be in the coronary sinus and the recording of a coronary sinus electrogram from the tip electrode (Levine and Goodale, 1950; Dalle, 1967) helped to establish the location of the catheter in Case 1. The electrogram in Case 1 showed
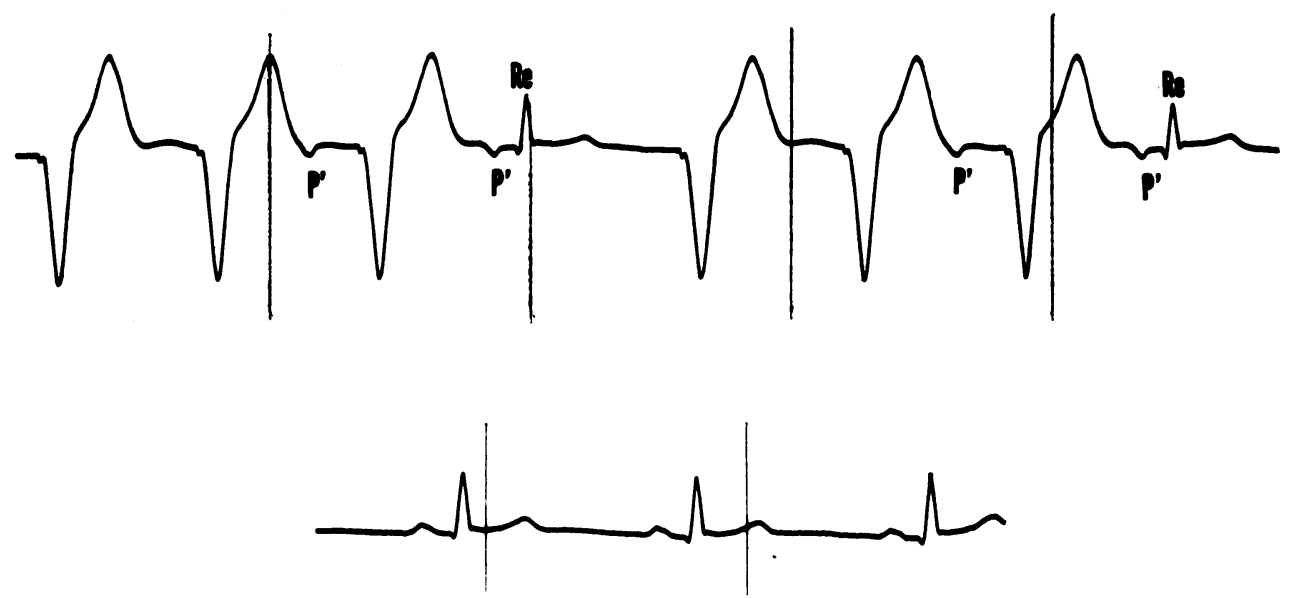

FIG. 7.-Case 3: Upper panel shows lead II recorded during apical right ventricular pacing demonstrating retrograde ventriculo-atrial conduction with inverted $\mathbf{P}$ waves $\left(\mathbf{P}^{\prime}\right)$. The third paced ventricular beat is followed by a retrograde $P$ wave sufficiently delayed (stimulus to $P$ wave interval $0.48 \mathrm{sec}$.) to permit re-entry producing a reciprocal (echo) beat with a QRS complex of supraventricular configuration and a $P-R$ interval of 0.14 sec. Lower panel shows lead II after apical pacing, with upright $P$ waves. 


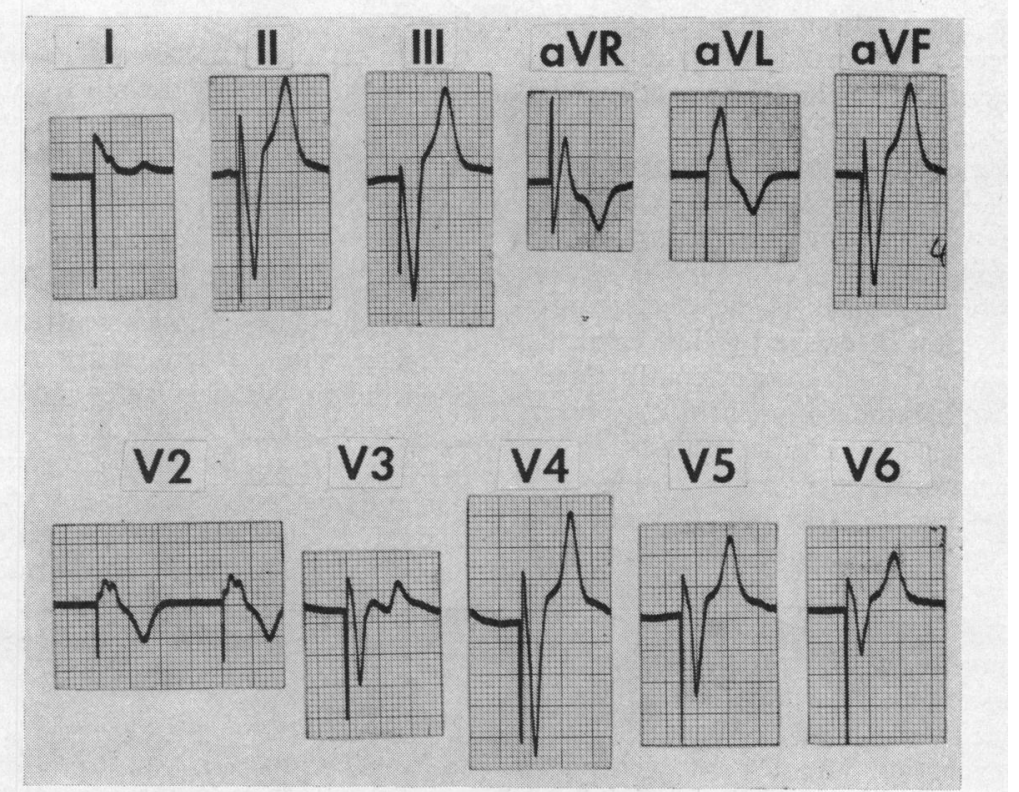

FiG. 8.-Case 4: electrocardiogram recorded several days after a permanent pervenous pacemaker was implanted showing right bundle-branch block pattern. There was no evidence of perforation, and the patient's clinical course was uneventful.

QRS complexes of high voltage associated with peaked "P" (flutter) waves which, together with a high rising threshold and a right bundle-branch block pattern during ventricular pacing, constitutes a triad suggestive of coronary sinus catheter position.

Pacing catheter perforation of the right ventricular wall, with migration of the catheter in the pericardial cavity, may enable pacing if there is contact with the left ventricular epicardial surface. Siddons and Sowton (1967) suggested that an alteration from left bundle-branch block to right bundle-branch block pattern may represent myocardial perforation, but we have never observed this change, and consider it a rare sign of perforation.

In two instances there has been the association of right ventricular endocardial pacing with a right bundle-branch block pattern in the absence of an obvious cause. Mower et al. (1967) also noted 3 such cases and concluded that a right bundle-branch block might occur during right ventricular pacing in the absence of perforation, which was confirmed at necropsy in one of their cases.

When the right ventricular outflow tract is stimulated a short distance below the pulmonary valve, the QRS complex in leads I and aVL may have an rS pattern which could be interpreted as a right bundle-branch block pattern if the praecordial leads are not examined. We have never seen a right bundle-branch pattern in the praecordial leads during right ventricular outflow tract pacing when leads I and aVL have displayed an rS pattern. Therefore, no conclusions regarding the presence of right bundle-branch block can be drawn from the rS pattern recorded in a single limb lead as assumed in Fig. 2 of the report by Mower et al. (1967).

Ample evidence exists that excitation penetrates the His-Purkinje specialized conduction system during ventricular pacing. Clinically the relatively frequent occurrence of retrograde $P$ waves during ventricular pacing in subjects with normal and impaired atrioventricular (AV) conduction (Samet, Castillo, and Bernstein, 1967; Castillo and Samet, 1967) constitutes prima facie evidence of retrograde activation of the bundle of His and the AV node. When only partial penetration into the conduction system (concealed conduction) occurs, the physiological effects may only become apparent by their influence on the subsequent supraventricular impulse (Langendorf et al., 1965). Lister et al. (1965) showed, by means of ventricular activation maps during epicardial pacing at various sites on the dog's heart, that the amount of muscle activated by comparatively slow muscle conduction $(0.5$ to $1 \mathrm{~m}$./sec.) relative to the mass rapidly activated through the conduction system (3 to $4 \mathrm{~m}$./ $/ \mathrm{sec}$.) depends upon the site of the pacemaker (Hoffman et al., 1959; Hoffman, 1961). Furthermore, epicardial stimulation at the posterior base of the left ventricle (site 
labelled $\mathrm{C} 10$ on the ventricular activation maps) yielded rapid depolarization of the right ventricle before the left ventricle. These observations suggest the presence of a "Purkinje bridge" between the left and right ventricular conduction systems responsible for the rapid depolarization of the contralateral ventricle when pacing is achieved from a particular ventricular site.

Right bundle-branch block is the electrocardiographic representation of delayed right ventricular activation relative to the left ventricle. In Case 3 the incomplete right bundle-branch block, present before ventricular pacing was instituted and exhibited by the reciprocal beats formed during apical right ventricular pacing (Barold, Linhart, and Samet, 1968), indicates some degree of right ventricular activation delay. This activation delay, masked during right ventricular inflow and outflow tract pacing, only became apparent during right ventricular apical pacing. Such an unusual finding may be explained in terms of relatively early penetration of excitation into the left ventricular conduction system during right ventricular apical pacing. The more rapid left ventricular activation would then allow the terminal forces recorded in the electrocardiogram to originate solely from delayed right ventricular activation. Bilateral bundlebranch disease was probably responsible for complete heart block in Case 4, and if diffuse pathological involvement of the right His-Purkinje system is postulated, right ventricular activation delay and its electrocardiographic representation would occur because of multiple conduction blocks forcing the majority of right ventricular activation to be accomplished by relatively slow muscle conduction (Linenthal and Zoll, 1965).

When a right bundle-branch block pattern is encountered during pervenous ventricular pacing, a full twelve-lead electrocardiogram is needed to establish its existence. Coronary sinus stimulation may be excluded by the recording of a characteristic electrogram from the pacemaker electrodes (Levine and Goodale, 1950; Dalle, 1967). Positioning of the pacing catheter into the coronary sinus should always be avoided by advancing it to the pulmonary artery and withdrawing it to rest in the right ventricle, or by recording electrograms before ventricular pacing is instituted. Should a right bundlebranch block pattern be encountered during ventricular pacing, and coronary sinus stimulation has not been entirely excluded by the aforementioned methods and radiologically, we feel it is safer to introduce another catheter into the right ventricle if the patient cannot be "weaned off" the pacemaker. Then the catheter suspected of being in the coronary sinus may be withdrawn. This procedure removes the potential risk of asystole from the rapidly rising threshold of coronary sinus stimulation and the danger of catheter perforation of this thin-walled vessel.

\section{SUMMARY}

Right bundle-branch block patterns were recorded during pervenous ventricular pacing in two patients, whose pacing catheters were, in all likelihood, in the coronary sinus, and in the absence of an obvious clinical cause in an additional two patients. In the absence of coronary sinus stimulation and myocardial perforation with preservation of pacing, a right bundle-branch block occurring during right ventricular pacing appears to represent right ventricular activation delay due to disease of the conduction system of that ventricle.

\section{REFERENCES}

Barold, S. S., Linhart, J. W., and Samet, P. (1968). Reciprocal beating induced by ventricular pacing. Circulation, 38, 330.

Castillo, C., and Samet, P. (1967). Retrograde conduction in complete heart block. Brit. Heart f., 29, 533.

Dalle, X. S. (1967). Cardiac Pacing and Cardioversion. Symposium Presented by the American College of Cardiology and the Presbyterian University of Pennsylvania, p. 16. The Charles Press, Philadelphia.

Gordon, A. J. (1965). Catheter pacing in complete heart block: Techniques and complications. f. Amer. med. Ass., 193, 1091.

Hoffman, B. F. (1961). Physiology of atrioventricular transmission. Circulation, 24, 506.

_, Cranefield, P. F., Stuckey, J. H., Amer, N. S., Cappelletti, R. R., and Domingo, R. T. (1959). Direct measurement of conduction velocity in in situ specialized conducting system of mammallian heart. Proc. Soc. exp. Biol. (N.Y.), 102, 55.

Langendorf, R., Pick, A., Edelist, A., and Katz, L. N. (1965). Experimental demonstration of concealed AV conduction in the human heart. Circulation, 32, 386.

Levine, H. D., and Goodale, W. T. (1950). Studies in intracardiac electrography in man. IV. The potential variations in the coronary venous system. Circulation, $2,48$.

Linenthal, A. J., and Zoll, P. M. (1965). Ventricular fusion beats during electric stimulation in man-application to conduction velocity and anomalous AV excitation. Circulation, 31, 651.

Lister, J. W., Klotz, D. H., Jomain, S. L., Stuckey, J. H., and Hoffman, B. F. (1965). Effect of pacemaker site on cardiac output and ventricular activation in dogs with complete heart block. Amer. F. Cardiol., 14, 494.

Mower, M. M., Aranaga, C. E., and Tabatznik, B. (1967). Unusual patterns of conduction produced by pacemaker stimuli. Amer. Heart F., 74, 24.

Samet, P., Castillo, C., and Bernstein, W. H. (1967). Studies in $\mathbf{P}$ wave synchronization. Amer. F. Cardiol., 19, 207.

Siddons, H., and Sowton, E. (1967). Cardiac Pacemakers, pp. 33 and 60 . Charles C. Thomas, Springfield, Illinois. 